\title{
S5 Vertebra
}

National Cancer Institute

\section{Source}

National Cancer Institute. S5 Vertebra. NCI Thesaurus. Code C33502.

The fifth of five sacral vertebrae; it articulates with the coccyx. 